\title{
Leiomyoma cellulare in the broad ligament of the uterus
}

\author{
Dobrosława L. Sikora-Szczęśniak \\ Department of Obstetrics and Gynecology, Specialist Hospital in Radom, Poland
}

\begin{abstract}
There are only two reports on leiomyoma cellulare (LC) in the parametrium that have been published so far. Aim of the study was analysis of two cases of LC in the parametrium diagnosed postoperatively, and review of literature on the subject.

Case 1: A 50-year-old patient was operated on for LC located in the right parametrium and concomitant malignant tumour in the right ovary. Leiomyoma cellulare was resected, hysterectomy and bilateral appendectomy performed, and bilateral iliac and obturator lymph nodes excised. Case 2: A 46-year-old patient was operated on for giant LC, on the left side, reaching the retroperitoneal space in the meso- and epigastrium. Leiomyoma cellulare was resected, and hysterectomy and bilateral appendectomy performed. The patient was reoperated twice due to haemorrhage within 24 hours following the operation. A literature review found reports on two cases of LC in 29- and 50-year-old patients with LC in the parametrium, located on the right and left side, respectively.

Casuistic location of $L C$ in the parametrium justifies reporting the cases in the literature. Preoperative diagnosis of LC in the parametrium is difficult. Conservative treatment, i.e. myomectomy should be reserved for those patients who wish to maintain fertility.
\end{abstract}

Key words: leiomyoma cellulare in the broad ligament, retroperitoneal leiomyoma cellulare.

\section{Introduction}

Leiomyoma is a benign non-epithelial mesenchymal monoclonal neoplasm originating from smooth muscle cells of the myoblast or vascular wall of the myometrium or stroma composed of fibrous connective tissue [1].

Considering its uterine location, leiomyoma cellulare (LC) is mainly found in the uterine body, seldom in the uterine cervix; it is extremely rare in the ovary, and its location in the fallopian tube is highly sporadic.

Cases of LC located in the parametrium are also extremely rare, [2], and in the broad ligament LC occurs in $<1 \%$ of cases [3].

The suprafamily of transforming growth factors $\beta$ (TGF- $\beta$ ), both inhibiting and stimulating the growth of tumours, and the factors regulating fibrosis are the main contributors involved in leiomyoma formation. They also act as immunosuppressants and angiogenesis stimulants affecting the tumour microenvironment $[4,5]$. In addition, the proteins from BMP-1/mTLD subfamily, like bone morphogenic protein 1 and mammalian Tolloid are important regulators of extracellular matrix and antiangiogenic factor of the basement membrane perlecan [1]. Wolańska et al. found that stimulation of extracellular matrix formation seemed to be a stronger stimulant of leiomyoma formation than angiogenesis [6]. Another risk factor for $L C$ is the involvement of ge- netic factors [7]. Family histories of LC have proved that significantly increased expression of vascular endothelial growth factor A (VEGF-A) [8].

One of the histological subtypes of leiomyoma is leiomyoma cellular (LC) diagnosed in $5 \%$ of cases. Histologically it is characterised by a large dense aggregates of smooth muscle cells and their nuclei without atypia but with little mitotic activity up to 5 mitotic figures /10 HPF, and scarce components of connective tissue elements [2].

Immunohistochemistry of desmin, CD 10, and $\mathrm{H}$-caldesmon are the tests used to differentiate $\mathrm{LC}$ from stromal tumours of the uterine body and leiomyosarcoma (LMS). The researchers believe the prognosis of tumours is good when there is no clotting necrosis, mitosis is < 10 mitotic figures/10 HPV, and no cellular polymorphism is observed; the tumours whose mitosis is > 10 mitotic figures/10 HPV without polymorphism are thought to be malignant. If mitotic index is $\geq 5$ accompanied by atypia, the tumour is suspected to be malignantly proliferating [9]. The risk of LC to be transformed into malignancy is $0.1-0.8 \%$ [10].

The purpose of the study was to present two case reports on LC postoperatively diagnosed in the parametrium. In addition, we review literature reports on LC and leiomyoma located in the retroperitoneal space of the pelvis minor. 
The paper presents an analysis of the medical records of two patients treated on the gynaecologicalobstetric ward of the Regional Specialist Hospital in Radom. In both patients histopathological examination found LC located in the parametrium. Moreover, we review literature reports discussing the cases of leiomyoma and LC located in the broad ligament of the uterus.

The case of partial LC in the left parametrium in a 70-year-old woman, after past amputation of the uterine body without appendages performed at the age of 41 years was excluded.

\section{Case reports}

\section{Case 1}

The patient, N.E., aged 50 years, was admitted to the ward on 05.04.2005 for giant tumour of the appendages.

Gynaecological history: Menarche at the age of 13 years, menstruating regularly every 28 days lasting 4-5 days. Menopause at the age of 49 years (March 2004). Two natural deliveries, no history of miscarriage. Body mass $72 \mathrm{~kg}$, body mass index $(\mathrm{BMI})=23.2$.

Gynaecological examination: Scopy: the ectocervix of the vaginal section normal, muco-serous fluid scarce. Bimanual gynaecological examination: the uterine body not enlarged, the uterus displaced under the pubic symphysis by the tumour arising from the appendages.

Imaging diagnostics (06.04.2005): Transvaginal USG: the uterus size $62 \times 30 \mathrm{~mm}$, ovarian tumour (size $123 \times$ $112 \mathrm{~mm}$ ) on the right side of the uterus, of differential echogenicity, solid-cystic with multiple polypoid projections. A considerable amount of fluid in the rectouterine pouch. Abdominal USG: The liver, pancreas and spleen normal. The gall bladder shrunk over fine deposits. The kidneys normally located, the size and structure normal, without signs of urine retention or deposits collected in the renal calyx-pelvis system. The urinary bladder remodelled by the tumour in the pelvis minor. Lymph nodes not enlarged, no visible free fluid within the abdominal cavity.

Cytoscopy: The mucosa normal, the ureters' orifices normal, the back wall remodeled from outside, raised.

Rectoscopy: a small polyp $30 \times 14 \mathrm{~cm}, 3 \mathrm{~cm}$ in diameter, the rest unremarkable.

$X$-ray of the chest: No condensed foci visible within the pulmonary parenchyma. The heart and aorta normal.

Lab results within the norm, except for: CA-125 $455.94 \mathrm{U} / \mathrm{ml}$. WBC $4.0 \mathrm{~K} / \mu \mathrm{l}$, HGB $9.8 \mathrm{~g} / \mathrm{dl}$, HCT 33.6\%.

Urinalysis: Erythrocytes lixiviated in HPF.

Surgery (11.04.2005): Laparotomy was performed by midline inferior incision reaching over the umbilicus. It exposed a cystic-solid tumour in the right ovary extending $6 \mathrm{~cm}$ over the umbilicus. In the right parametrium a tumour was found: $60 \mathrm{~mm}$ in diameter, of smooth surface and consistency of softening myoma. The uterine body and the left appendages intact. The right appendages were resected with the tumour and bilateral iliac and obturator lymph nodes excised. Hysterectomy, left-side appendectomy performed and the tumour of the right parametrium resected. Greater omentectomy and appendectomy was performed. A sample of visceral peritoneum from the place of ovarian tumour nest and from the colic hepatic flexure was collected for further analysis. The patient received $2 \mathrm{U}$ packed red blood cells (PRBCs). The patient was discharged home on the sixth day following the surgery and referred for oncological treatment.

Microscopic and histopathological test results:

The right adnexia: Cystadenocarcinomaclarocellulare Gll ovarii. Emboliaecarcinomatosaesolitariaevasorum. The tumour confined to the ovarian wall, the serous membrane free from cancerous infiltration. Oviductus. Tumour in the right parametrium: Leiomyoma cellulareparametrii. No metastases to the lymph nodes were found.

\section{Case 2}

The patient M.R., aged 46 years was, admitted to the ward on 29.11.2011 for a giant tumour in the abdominal cavity, growing circumference of the abdomen, and flatulence for 2 months.

Gynaecological history: Menstruation from the age of 15 years, regular, every 28 days, lasting 5-6 days; menopause 01.11.2011. The patient gave birth three times, natural deliveries, one miscarriage. Body mass $72 \mathrm{~kg}$, $\mathrm{BMI}=26.4$.

Gynaecological examination: Scopy: the uterine cervix elevated in the roof of the vagina, without lesions. Muco-serous fluid scarce. Bimanual gynaecological examination: the uterine body not enlarged, displaced under the pubic symphysis by the tumour filling the abdominal cavity, its fundus reaching the costal arches.

USG: Tumour of solid structure, with non-echogenic spaces inside. The clinical picture suggesting for uterine myoma.

Lab results normal, except for CA125 - $33.97 \mathrm{U} / \mathrm{ml}$, CEA - $2.17 \mathrm{U} / \mathrm{ml}$

Surgery (08.12.2011): Laparotomy performed by midline inferior incision reaching over the umbilicus. It exposed tumour $300 \times 300 \times 200 \mathrm{~mm}$ located interligamentously, on the left side filling the mesogastrium and epigastrium. The uterine body of normal size and smooth surface, displaced rightward. The appendages: both ovaries enlarged, with cysts; the fallopian tubes intact. Lymph nodes not felt on palpation. The tumour of the left parametrium was resected, the uterine body, the cervix and appendages on both sides were excised. The patient was reoperated on the same day twice due to haemorrhage to the peritoneal space and oligov- 
olemic shock. In addition, the left uterine artery was ligated. Because of anaemia and coagulopathy implied by lab results the patient received $13 \mathrm{U}$ PRBCs and $8 \mathrm{U}$ of fresh frozen plasma (FFP) and Novo-Seven (1 vial $2 \mathrm{mg}$ ). The patient was discharged home on the $11^{\text {th }}$ day following the surgery.

Microscopic and histopathological test results:

- The uterine body: Endometrium in stadioproliferationis. Endometriosis.

- The uterine cervix: Erosioglandularis in statuepidermisationis cum inflammatione.

- The left appendages: Cystesfolliculares ovarii. Oviductus.

- The right appendages: Cystisfollicularis ovarii. Oviductus.

- Tumour in the right parametrium: Leiomyoma cellulare. Slight focal atypia of the nuclei.

\section{Review of literature}

Chmaj-Wierzchowska et al. presented a case of LC in the right parametrium in a 29-year old woman [2] The lesion, $60 \mathrm{~mm}$ in diameter was preoperatively diagnosed as a leiomyoma of the parametrium or the uterus. Laparoscopy was performed to remove the tumour.

The other case of LC was described by Sharma et al. [11]. Leiomyoma cellulare was diagnosed in a 50-yearold woman. The giant mass of the tumour and degenerative changes led to a preoperative clinical diagnosis of ovarian tumour. Laparotomy was performed to resect the uterus (normal size) and appendages (intact). Histopathological examination found LC with the foci of mitosis (2-3 mitotic figures/10 HPF).

The actual incidence of leiomyomas located in the broad ligament is unknown [12]. Until February 2008 only 46 cases of LC located in the retroperitoneal space were reported, and $73 \%$ of retroperitoneal LCs were located in the pelvis minor [13].

The signs and symptoms due to LC include pains, flatulence, irregular menstruation, infertility, and uterine bleedings during the post-menopausal period [3].

Leiomyomas in the parametrium are large sized because their growth is often asymptomatic. They can displace the uterus in the other direction and compress adjacent structures ("the effect of mass") and produce symptoms from the urinary and alimentary tract [14-17].

The review of literature suggests that the symptoms usually occur 2-8 months prior to surgical operation $[13,17]$.

For preoperative diagnostics and surgery itself it is extremely important to locate the ureter. Leiomyoma connected to the lateral wall of the uterus moves the ureter downwards and sideward. However, the actual leiomyoma can grow anywhere around, and the ureter can run over or under the tumour, and even through its capsule. Contrast-enhanced CT prior to surgery or urography can visualise the ureter's location. In addition, ureter catheterisation is recommended [18, 19].

Massive bleeding from the vessels after a tumour of the parametrium has been removed is a serious complication, and is a strong indication to re-operate on the patient, as it was the case in our second patient.

Leiomyomas of the parametrium that grow large also produce various retrogressive changes like degenerations and foci of necrosis. Mucoid lesions and calcified foci (in haemorrhages and necrotic foci) are most frequently observed in case of leiomyomas located in the broad ligament [12].

\section{Discussion}

Leiomyoma cellulare is the most frequent benign tumour of female genital organs and the uterus. Outside the uterus $(<1 \%)$ it is most frequently located in the broad ligament of the uterus [3].

In terms of the various imaging techniques being used, i.e. USG, CT, and MRI, it is MRI which is the most useful [21].

Transvaginal USG can show areas of altered echogenicity depending upon the degree of degeneration, fibrosis or calcification. MRI is a more precise technique to visualise those conditions. Transvaginal ultrasound can visualise the uterus and ovaries differentiated from leiomyoma of the parametrium. In T1-dependant scans leiomyomas give less intensive signals resembling uterine muscle [22]. Leiomyomas containing the areas of degeneration and mucoid necrosis they can be seen as the regions of high intensity in T2-dependent scans [16].

Leiomyomas of the uterus concomitant to leiomyomas of the parametrium can distort the anatomical structure of the pelvis, and like degenerations in leiomyomas can produce complications and make differential diagnosis with ovarian malignancies more difficult [15, 23, 24].

Moreover, preoperative diagnosis is complicated because of concomitant diseases affecting internal reproductive organs, as was the case in our second patient. In the case of leiomyoma or LC in the parametrium higher concentrations of CA-125 also can make preoperative diagnosis more difficult $[11,14]$. Preoperative diagnosis of leiomyoma in the parametrium is only possible when the tumour has been biopsied guided by USG/CT and histopathological results ready prior to the operation [25]. However, imaging diagnostics are not always completed, due to financial reasons [3].

Leiomyomas of the parametrium were often very large, and weighing from 3,000 $\mathrm{g}$ to $13,000 \mathrm{~g}[12,26]$.

Young women had operations sparing their fertility, i.e. myomectomy was often performed $[2,3,18]$. 
Transfusion of blood and blood products (1-4 $\mathrm{U}$ PRBCS) was also mentioned in the literature reports $[3,18,26,27]$.

Surgical operations often require participation of multi-specialist operators [13]. It was the case in case 2 presented above.

Many authors state that LCs presents a separate clinical phenotype in comparison to conventional leiomyoma, and genetic features common to LMS [28-30]. Deletion of chromosome 1p, typical of LMS was observed in $23 \%$ cases of LC [28].

Considering "borderline" pathological character of LC many authors have recently suggested longer clinical monitoring of patients with LC. Therefore, the recommendation that conservative treatment should be restricted to those women who want to maintain fertility is fully justified [30, 31].

\section{Conclusions}

Leiomyomas cellulare casuistically detected in the parametrium justify their presentation in literature. They are difficult to diagnose preoperatively. Conservative treatment, i.e. myomectomy should be restricted to patients willing to maintain fertility.

\section{Disclosure}

Author reports no conflict of interest.

\section{References}

1. Auguściak-Duma A, Sieroń AL. Molekularna charakterystyka guzów leiomyoma uteri na przykładzie wybranych składników macierzy pozakomórkowej. Postępy Hig Med Dośw 2008; 62: 148-165.

2. Chmaj-Wierzchowska K, Buks J, Wierzchowski M, et al. Leiomyoma cellulare in the broad ligament of the uterus - case report and review of literature. Ginekol Pol 2012; 83: 301-304.

3. Bakari F, Sulayman HU, Avidime S, et al. Huge broad ligemant leiomyoma: a case report. Case Reports in Clinic Med 2015; 4: 55-59. http:// creativecommons.org/licences/by/4.0/.

4. Luo X, Ding L, Xu J, et al. Gene expression profiling of leiomyoma and myometrial smooth muscle cells in response to transforming growth factor-B. Endocrinology 2007; 146: 1097-1118.

5. Laping NJ, Everitt J, Frazier KS, et al. Tumour-specific efficacy of trans forming growth factor-beta RI inhibition in Eker rats. Clin Cancer Res 2007; 13: 3087-3099.

6. Wolańska M, Małkowski A, Romanowicz L, et al. Does vascular endothelial growth factor participate in uterinaemyoma growth stimulation. Eur J Obstet Gynecol Reprod Biol 2012; 164: 93-97.

7. Stewart EA, Morton CC. The genetics of uterine leiomyomata: what clinicians need to know. Obstet Gynecol 2006; 107: 917-921.

8. Chang CC, Hsieh YY, Lin WH, et al. Leiomyoma and vascular endothelial growth factor gene polymorphisms: a systematic review. Taiwan J Obstet Gynecol 2010; 49: 247-253.

9. Madej P, Madej JA. Patomorfoza mięśniaków macicy u kobiet. Gin Pol Med Project 2008; 3: 32-42.

10. Markowska A, Słomko Z. Mięśniaki macicy. In: Ginekologia. Słomko Z (ed.). Wyd. Lek. PZWL, Warszawa 2008; 148-165.

11. Sharma P, Zaheer S, Yadav AK, et al. Massive broad ligament cellular leiomyoma with cystic change: a diagnostic dilemma. J Clin Diagn Res 2016; 10: ED01-ED02.
12. Godbole RR, Lakshmi KS, Vasant K. Rare case of giant broad ligament fibroid with myxoid degeneration. J Sci Soc 2012; 39: 144-146.

13. Soliman AA, ElSabaa B, Hassan N, et al. Degenerated huge retroperitoneal leiomyoma presenting with sonographic features mimicking a large uterine leiomyoma in an infertile woman a history of myomectomy: a case report. J Med Case Reports 2011; 5: 578.

14. Jagtap SV, Gupta A, Kshirsagar NS. Broad ligament myoma mimicking as ovarian tumour. Sch J App MedSci 2014; 2: 258-260.

15. Preeti B, Dinesh G. A case of massive broad ligament leiomyoma imitating an ovarian tumour. J Clin Diagn Res 2014; 8: 136-137.

16. Rajanna DK, Pandey V, Janardhan S, et al. Broad ligament fibroid mimicking as ovarian tumour on ultrasonography and computer tomography scan. J Clin Imaging Sci 2013; 28: 23-28.

17. Khodry MM, Tamam AA. Broad ligamentarymyoma in post menopausal woman. Middle East Fert J 2014; 19: 144-146.

18. Chaudhari HK, Parulekar SV. Large broad ligemant leiomyoma. J Postgr Gynecol Obstet 2015; 3 (6). Available from: http://www.jpgo.org/2016/06/ large-broad-ligament-leiomyoma.html.

19. Emerich J. Operacyjne leczenie mięśniaków. W: Mięśniaki macicy. Markowska J (ed.). MedPharm, Wrocław 2008; 73-83.

20. Parker WH. Uterine myomas: an overview of development, clinical features and management. Obstet Gynecol 2005; 105: 216-217.

21. Fasih N, Shanbhogue AKP, Macdonald GB, et al. Leiomyomas beyond the uterus: unusal locations, rare manifestations. Radiographics 2008; 28: 1931-1948.

22. Jeong GA. Retroperitoneal leiomyoma of the uterus mimicking sarcoma in perimenopausal women: case report. J Menopaus Med 2014; 20: 133 137.

23. Masood SN, Masood Y, Mathrani J. Diagnostic dilemma in broad ligament leiomyoma with cystic degeneration. Pak J Med Sci 2014; 30: 452 454

24. Mallick D, Saha M, Chakrabarti S, et al. Leiomyoma of broad ligament mimicking ovarian malignancy - report of a unique case. Kathmandu Univ Med J 2014: 47: 2019-221.

25. Moyle PL, Kataoka MY, Nakai A, et al. Nonovarian cyst lesions of the pelvis. Radiograpphics 2010; 30: 921-938

26. Nayki Ü, Cenk N, Pasa U, et al. A rare case of a giant cystic leiomyoma presenting as a retroperitoneal mass. Iran J Reprod Med 2014; 12: 831834.

27. Goel N, Laddad M. A rare case of giant broad ligament fibroid with cervical fibroid mimicking ovarian tumour: interesting case report. Int J Rec Trend Sci Technol 2014; 10: 208-209.

28. Hodge JC, Pearce KE, Clayton AC, et al. Uterine cellular leiomyomata with chromosome $1 p$ deletions represent a distinct enlity. Am J Obstet Gynecol 2014; 210: 572e1-7.

29. Taran FA, Weaver AL, Gostout BS, et al. Understanding cellular leiomyomas: a case-control study. Am J Obstet Gynecol 2010; 203: 109e1-6.

30. Guraslan H, Senturk MB, Helvacioglu C, et al. Recurent cellular leiomyoma 10 years after total abdominal hysterectomy. J Obstet Gynaecol 2015; 35: 854-855

31. Guan R, Zheng W, Xu M. A retrospective analysis of the clinicopathologic characteristics of uterine cellular leiomyomas in China. Inter J Gynecol Obstet 2012; 118: 52-55. 